\title{
Evolution of calcium carbonate polymorphs in acidic solutions in the presence of dissolved metals *
}

\author{
YOUNGJAE KIM $^{1}, \mathrm{KE} \mathrm{YUAN}^{2}$, BEKTUR ABDILLA ${ }^{3}$, \\ VINCENT DE ANDRADE ${ }^{4}$, NEIL C. STURCHIO ${ }^{3}$, SANG SOO \\ LEE $^{1}$, PAUL FENTER ${ }^{1}$
}

${ }^{1}$ Chemical Sciences and Engineering Division, Argonne

National Laboratory, Lemont, IL, USA

${ }^{2}$ Chemical Sciences Division, Oak Ridge National

Laboratory, Oak Ridge, TN, USA

${ }^{3}$ Department of Earth Sciences, University of Delaware, Newark, DE, USA

${ }^{4}$ Advanced Photon Source, Argonne National Laboratory,

Lemont, IL, USA

Calcium carbonate $\left(\mathrm{CaCO}_{3}\right)$ is commonly found in geological settings as three polymorphs. Calcite is the most stable phase while two other metastable polymorphs, aragonite and vaterite can be dominant under certain circumstances. These calcium carbonate minerals serve as a major sink for various metal ions in rocks, soils and shells of marine organisms. The sequestration of dissolved heavy metals (e.g., $\mathrm{Pb}^{2+}$ ) can occur via mineral replacement reactions.

We studied the evolution of vaterite and calcite during reaction with acidic solution containing $\mathrm{Zn}^{2+}$ and $\mathrm{Pb}^{2+}$ ions using in situ optical microscopy, ex situ scanning electron microscopy with energy dispersive X-ray spectroscopy, and ex situ nano-tomography with the transmission X-ray microscope at APS. When vaterite crystals were reacted with the solutions, (hydrous) lead and zinc carbonates nucleated predominantly on the outer part of the hosting minerals, resulting in the formation of pseudomorphic shells. When calcite crystals were reacted, secondary carbonate phases initially formed on the calcite surfaces followed by the internal growth of lath-shaped crystals that were preferentially oriented along the edges of calcite [1]. When vaterite and calcite crystals were reacted simultaneously, the replacement reaction occurred mainly in vaterite, indicating their different reactivities. These results demonstrate that the crystallography and solubility of the $\mathrm{CaCO}_{3}$ phases play a crucial role in their metal uptake mechanism in acidic solution.

Reference: [1] Yuan et al. (2016) Environ. Sci. Technol., 50, 12984-12991.

* This work was supported by U.S. Department of Energy, Office of Science, Office of Basic Energy Sciences, Chemical Sciences, Geosciences, and Biosciences Division, Geosciences Program. 